\title{
Co-construction of the tourist experience in social networking sites: Two forms of authenticity intertwined
}

Dhis document has been downloaded from TamPub.uta.fi a The Institutional Repository of University of Tampere

\author{
Li Wang \\ University of Tampere, Finland \\ Pertti Alasuutari \\ University of Tampere, Finland
}

\begin{abstract}
Although social networking sites have become an important outlet for tourists to share their experiences - typically through mobile phones during their trips, communication of tourist experience in the context of social networking sites has been overlooked so far. In this article, we particularly focus on the ways sightseeing oriented tourist experience is communicated in social networking sites. By looking at the naturally occurring data generated by the users, we examine the ways the tourist experience is communicated in this particular context by using the analytical concept of authenticity. Based on the findings of language use strategies and interaction patterns in the data, we propose the concept of experientialisation to understand the tourist experience sharing in social networking sites. In that way, the article makes a contribution to the literature on authenticity.
\end{abstract}

\section{Keywords}

authenticity, Internet, social media, social networking site, tourist experience

\section{Introduction}

Along with the adoption of social media and mobile technologies, social networking sites (SNSs) have become an important outlet for tourists to share their experiences of leisure and recreation. It has become a common phenomenon that people tell about their touristic encounters or sightseeing 
experience in SNSs during their trips, typically through mobile phones. Thus using social media and mobile technologies has become a new dimension of engaging with tourism discourse, which leads to a great expansion of tourism as an institution and fundamental changes within it. For instance, it has been commonly recognised that the use of social media is changing the travel experience. The distinction between going away and being at home is contested when tourists are able to constantly catch up with their everyday life during their journey. These changes can be evidenced by the recent development of the conceptualisation and theorisation of the tourist experience and of the meaning of tourism, which has become broader and more inclusive (Urry, 2003; Jansson, 2002; Jansson, 2007; Lean, 2012; Uriely, 2005; White and White, 2007; Larsen et al., 2007).

There has been a growing interest in the research on social media usage in tourism in the past years (Zeng and Gerritsen, 2014), including studies on selfie-taking (Dinhopl and Gretzel, 2016b; Pearce et al., 2016), post-trip experience sharing (Kim and Fesenmaier, 2015), and tourism destination branding (Oliveira and Panyik, 2015; Buhalis and Foerste, 2013). Younger people have been reported to be more active in using social media for travel planning and experience sharing (Guerra et al., 2015), but it is quite popular among all tourists: more than one fifth of all international travellers use social media as a travel information source (IPK International, 2015: 35). Yet, although interaction in SNSs while travelling has become an important part of the tourist experience, it has been overlooked in existing research. The existing studies on SNSs used for touristic purposes mainly focus on individual behaviour, e.g., on the motivations and intentions of the tourists' use of SNSs (Parra-López et al., 2011; Huang et al., 2010; Munar and Jacobsen, 2014) and on how tourists use the online information for travel planning (Cox et al., 2009; Xiang and Gretzel, 2010; Bizirgianni and Dionysopoulou, 2013; Buhalis and Law, 2008). On the other hand, in tourism studies scholars have conducted textual analyses of tourism discourses in the Internet, for instance by studying travel blogs or videos on Youtube (Mkono, 2011; van Nuenen, 2015; Kane, 
2012; Tussyadiah and Fesenmaier, 2009). However, communication of tourist experience in SNSs has been underexplored so far despite its popularity. Besides, in the empirical studies on travel blogs and Youtube, the Internet is solely taken as a data source. Therefore, by studying communication in SNSs as part of, and potential influence on, the tourist experience, this article makes a contribution to the literature in this area.

In this article we particularly focus on the ways sightseeing oriented tourist experience is communicated in the context of SNSs. In this instance 'context' is understood as a social construct (Berger and Luckmann, 1966). It is neither dependent on physical and material factors such as technological affordances, nor fixed with a certain set of parameters in the objective sense. Instead, as a social construct, context is intersubjective and produced during individuals' concrete activities, - i.e., textual interaction in the case of SNSs.

The research material consists of naturally occurring data generated by the members of the online communities being studied. We examine the individual members' mundane, ordinary social contacts and engagements in the online sharing of tourist experience. The investigation focuses on the ways the tourist experience is communicated in this particular context. As will be shown in the next sections of this article, we argue that the inferences drawn from the online conversations call for a rethinking of the core of tourism as a cultural phenomenon: authenticity. Despite the common recognition of the effects of technology-mediated contexts and the activeness of touristsin the construction of authenticity, there is lack of first hand research on multiple Internet users' interaction dealing with tourist experience. The dearth of research prevents us from properly understanding how authenticity is constructed in technology-mediated contexts, which is the motivation of this study.

The rest of this article is structures as follows. The next section reviews previous research relevant for this study. Then, after introducing the data and methods, we present and interpret the 
empirical results. The final section discusses how this article contributes to the understanding of the tourist experience and authenticity.

\section{Representations of the Tourist Experience and Technology Use}

Although there is scarcity of research on the online construction of the tourist experience, the last decade has witnessed a surge of scholarly interest in how tourism is intertwined with digital and networked technologies and how, consequently, tourists have gained a stronger role in the discursive field. These studies provide a relevant background for the paper at hand.

One of the emerging phenomena related to technology use is the increasing popularity of tourist videography. According to Dinhopl and Gretzel (2015, 2016a) taking videos enhances the immersion in the tourist experience compared with taking photos. In the case of tourist photography, when tourists practise the ritual of getting together and checking the camera to examine the photos they have taken, the event becomes a celebration of the pictures instead of immersing in what they are seeking with traveling. According to the authors video-taking is different in this respect in that it makes the immersion stronger and less mediated. That is because the video camera users do not need to perform or pose for the camera. The authors emphasise that the videos focus on storytelling and tourist activities rather than tourist destinations.

Tussyadiah and Fesenmaier (2009) make another point about how the tourist experience is mediated in videos shared on Youtube. Their analysis of the representations of New York City, i.e., the cityscapes, destinations, and touristic activities, shows that the most popular videos can be understood as markers constructing the worthiness of the sights in New York City. In this sense, according to the authors video as a cultural artefact is not so different from postcards or souvenirs. Furthermore, place representation in the videos stimulates the tourists' imaginative hedonism. For the viewers who have never been to New York, the videos are perceived as a source of fantasy; for the viewers who do have been there, they bring back memories. 
Another instance related to tourists' technology use - in particular, mobile devices, digital cameras and photo-sharing websites - is the popularity of the tourist selfie, which sometimes even causes challenges and negative consequences (Pearce and Moscardo, 2015). The work of Dinhopl and Gretzel (2016b) shows that in the culture of tourists' selfie-taking, the self becomes a product of othering that is both produced and consumed by the tourist.

Besides explaining and theorising the technological mediators and new social practices, oftentimes the studies in this area contribute to the literature on authenticity and authentication. As first discussed by MacCannell (1976/1989), for tourists seeking authenticity means that they want to experience original, real, and genuine sites. With the rise of a wide range of phenomena in modern tourism such as camping, beach holidays and adventure seeking, scholars have developed further the concept of authenticity (Cohen, 1988; Jansson, 2002; Jansson, 2007; Quan and Wang, 2004; Wang, 1999; Uriely, 2005). Alongside the development and expansion of the framework of authenticity, some scholars have switched their attention to authentication, which refers to the social process through which authenticity is produced (Lugosi, 2016; Cohen and Cohen, 2012).

A number of studies examine the way the tourist experience is represented in the Web . For instance, Kane (2012) studied the adventurer tourists' blogs and the mountaineering guiding companies' websites. Authenticity in this case derives from the mountaineering adventure that refers not only to the romanticism and uniqueness in the adventure's destination - for instance Mount Everest as a 'truly global iconography' - but also to the hardships and challenges that the mountaineering tourists confront in their journey. Difficult climates, facility conditions, and lifethreatening dangers are accounted in the companies' websites and the professional tour guides' profiles not only to arouse the interests of adventure tourists but also to affect the tourists' own narratives. When reproducing their stories in their own blogs, the tourists seek to build up their identity as adventurers by for instance telling how they went through hardships with admirable braveness and decisiveness. Their portrayed identities are designed to be 'sellable' to the public, 
especially when the adventurers were sponsored. In contrast, the reality of how they follow the restrictions by the guiding companies as the 'guided' ones in a safety service bubble is largely obscured.

Similarly, van Nuenen (2015) shows how authenticity is also a selling point for the professional travel bloggers to establish and promote their images for self-branding and marketing purposes. By using their personal stories and the travel experience, the bloggers allude to the value of freedom to arouse the audience's aspiration for the lifestyle, for instance by telling how they escaped their everyday life and left their home in the western world and travelled to the east. The travel stories are composed with a bias towards commercial interests and a marketing scheme. The photos capture both the tourist destinations and the traveller in the same frame - as a strategy to 'connect place to face' (p.13) to build up the market value of oneself.

By examining the online tourist reviews of African cultural restaurants, Mkono (2011) shows how authenticity is constructed with language use in the touristic experience of food as 'scary', 'strange', 'dangerous', and so on. Such otherness is neutralised by telling that Western food is offered in the menus. Therefore, familiarity and novelty are balanced for safety-seeking minds. Authenticity is constructed in relation to the ordinariness of Western culture.

To conceptualise authentication with both human and non-human actors taken into account, Lugosi (2016) proposes that authentication starts with the objectification of an experiential object i.e., certain entity to be evaluated. Experiential object here is a broad concept, which could mean a destination, location, social encounter, events, or objects. In the objectification process, technology plays an important role. For instance, online reviews, sharing of the tourist experience, and search engines are all ways of objectification and codification of tourism objects. Technology, or 'sociotechnological systems', provides the context for authentication. In this framework, technologyfacilitated authentication is described with three techniques: foregrounding, obscuration, and selective coupling-decoupling of information. 
On the whole, previous research raises the question of how technology-mediated context affects the way the tourist experience is constructed. From this viewpoint, studying the communication of the tourist experience in the context of SNSs is particularly relevant, because in the studies discussed above, the interactive character of present-day Internet is ignored. Yet meaning making is a collective process after all (Berger and Luckmann, 1966; Heritage, 1984). This is an important point to stress also regarding the literature on 'co-creation of value' developed by scholars of tourism management. It means that instead of being only passive recipients of the marketing values of tourism products and services, tourist customers have an active role in creating them (Rihova et al., 2015; Oliveira and Panyik, 2015; Buhalis and Foerste, 2013; Lugosi, 2014; Wozniak et al., 2016).

Moreover, the context in these studies usually refers to the touristic activities such as mountaineering. While websites and blogs serve as valuable data sources, they also function as the immediate context for communication, and the Internet cultures therein also place constraints on how authenticity is interpreted. In previous research, either the role played by the online context has largely been ignored, or scholars refer to 'technology' to address the mediation contexts (Neuhofer et al., 2014; Lugosi, 2016), which is a rather large and vague concept. As numerous studies have reported, social meanings are dependent on context. That is, it is difficult to understand the emerging activities and phenomena universally for all kinds of technologies and applications. Therefore, instead of asking the question of technological mediation in general, it is better to scrutinise the tourist experience in particular contexts, such as SNSs in the study at hand.

\section{Data and Methods}

The text corpus of this study is collected from two popular SNSs: Facebook and Google+. The data were collected from among one of the authors' circle of friends on these two sites during the five and a half years from March 2010 to September 2015. ${ }^{1}$ The collected texts consist of 275 threads, or 
2,382 posts and 235 photos, which recorded 35 trips made by 20 different individuals. We particularly focused on the threads that gather at least 5 pieces of comments, which allow us to better scrutinize how meaning is made in the interaction of several individuals. There are 90 participants in the Facebook community and 58 in the Google+. ${ }^{2}$ Majority of the 35 trips are within Europe, whereas 6 of them are across continents. They mainly take place during public holidays and weekends.

The author who collected the texts is a Chinese woman in her 30's who currently works as a post-doc researcher at a university in Europe. Around one third of the Facebook friend circle consists of university students and researchers in European countries, one third acquaintances from hobby pursuits in a local dance school and cat owners in the city, plus one third Chinese friends in different regions in the world and the significant others. Compared with the friend circle in Facebook, the social relationships in the Google+ group are mostly weaker ties, only less than one third are acquaintances in the author's real life, who are mostly engineers and early adopters of technology products and applications. The majority of the Google+ group live in different European countries. The demographic profiles of the participants from the two sites are greatly diversified across a wide range of age and ethnicity, but the majority of them do have higher education background and stable income. Roughly half of the posts were collected from Facebook and the other half from Google+.

The research material is scrutinized by applying discourse analysis (DA) (Potter, 1996; Potter and Wetherell, 1987; Potter and Wetherell, 1994). DA is a general concept encompassing several distinct approaches. The one adopted in this study is grounded in the traditions of both the sociology of knowledge and cultural studies. It treats text and talk as social practices addressing social and sociological problems. In essence, there are two important foci in the analysis. One is the identification of 'interpretative repertoires' from people's accounts on the basis of similarities found across individual accounts (Potter and Wetherell, 1987; Gilbert and Mulkay, 1984); in this case the 
focus is on repertoires of authenticity. This involves recognisable routines and cultural categories through which institutionalised social practices are sustained. The other focus is to discover variations in the construction of discourse in term of linguistic resources or organisation of arguments both within and between the cultural categories (Potter and Wetherell, 1987; Potter and Wetherell, 1994).

The well-established concept of authenticity is used as an analytical tool for the empirical study. By drawing upon the literature of the conceptualisation of authenticity, 'object-related authenticity'(MacCannell, 1976/1989; Cohen, 1988) and 'existential authenticity' (Wang, 1999; Steiner and Reisinger, 2006) are applied to examine the representation of the tourist experience. Though the line between the two terms is rather fine and negotiable, as discussed in Lau (2010), the two concepts show different orientations in that the former is oriented towards engagement with markers signifying the worthiness and authenticity of an alien culture, such as touristic sights and destinations, whereas the latter concerns the tourist's self and sentiments instead of tour objects.

We can also say that the analysis focuses on a moral aspect of language use regarding authenticity. In other words, authenticity is taken as an 'experiential morality' - that is, 'a kind of habitus or an unreflective disposition of everyday social life' (Zigon, 2008: 17). The communication of authenticity involves people's evaluation and investment of emotion, though agents are not necessarily conscious that they are engaged in moral communication. Some types of touristic pursuits are valued to a greater extent than other ones. How the tourist experience is communicated is associated with this predisposition of valuation. The analysis focuses on the descriptive statements of experiences, such as comments on what is good, favoured, or valued, along with general evaluation and judgement with respect to what tourists apparently ought to do that are not necessarily based on deliberation.

Regarding research ethics, the ethical guidelines of the Association of Internet Researchers (AoIR) (Ess and AoIR, 2002; Markham et al., 2012) were followed. Of the principles set forth in 
the AoIR documents, the most important is to avoid any harm to the participants. In the present case, the members of the online communities studied can be treated as informants or subjects like in conventional in social science. The ethical treatment follows the usual standard of anonymity protection and informed consent.

\section{Construction of Object-related Authenticity}

Regarding the tourist experience, object-related authenticity can be seen in the data in how sights are morally valued in the online discussions. One evident instantiation is the use of linguistic markers showing how these sights and attractions are favoured strongly in the group members' communication. When actors refer to their viewing of sights and attractions, they are presented as more obligatory than optional. Examples include 'Still have to see the tulips and several sights/museums'; 'but i must check out the louvre', '[Cultural show in Tokyo] Just have to be experienced' (emphasis added).

There are also other ways in which the valuation of the sights is communicated. Instead of stating 'I have to visit Louvre', the actors refer to the sights without explicit valuation. For one thing, snapshots indicate the importance of sights. In more than half of the 35 trips, the actors updated their cover or profile photos with travel photos. The importance of certain sites can also be identified in the accounts of peak experiences with extensive use of place referents. Here are some examples:

'Cooling off in the infinity pool!' [in Marina Bay Sands in Singapore].

'When in Rome, soak in the grandeur of the Flavian amphitheatre.'

'Pisa: not just about the Leaning Tower... there's also a lovely cathedral, some tasty gelato/sorbet from Gelateria De' Coltelli, live music along Ponte di Mezzo (where this pic was taken).' 
Authenticity is signified and objectified with the place referents such as Flavian amphitheatre and the Leaning Tower. These symbols represent authenticity and make it specific. Institutionalised sights and attractions are referred to in all the trips in the data.

Authenticity is constructed not only by the tour sights but also by unmarked sites and practices such as the local public transport, commodities, and shops. One illustration is that a large amount of the published photos is associated with sites not marked for tourists, such as random street views, food and restaurants, personal purchases and possession, and public transport. The sense-making at the agency level is not determined by institutionally articulated worthiness, though it is influenced by it. Another illustration is the actors' reports on the immersive experience such as 'Metro in bruxelles is easy to figure out, kinda like paris', 'This is slightly faster than the pendolinos in finland but oh so smooth', and 'eating and drinking around this part of Europe are much cheaper'. Besides the sights and attractions, many of the accounts of authenticity focus on unmarked consumer activities such as eating, shopping, using public transportation, and experimenting hotels. In these cases, the tourist is a sightseer but also a consumer. The tourist experience is not only visual but also sensory in general. Extract 1, below, provides a relevant example.

\section{Extract 1. Eating in a French Restaurant ${ }^{3}$}

Amy: It's true what they say about ordering steaks in france: ask for medium and you get rare. Ask for rare and you get raw. Usually in other countries i would ask for medium-rare, but.... [there is an accompanying image of food]

Amy: I asked for medium here and this is one of the rarest steaks i've eaten. Pretty good though. Oh and is it rude to take pics of food in french restaurants?

Peter: Is it possible to be rude in France? 
Amy: I don't know, i've been trying to get the bill for the last 15 min. Already late in meeting a friend....

Nina: Walk out, they will catch you :-D!

Gary: Right... i've done that too. once, they took 20 min, since i asked the bill. so i got up and left. before i reached the door, they brought me the bill, and asked me to pay it :P

Miranda: In which restaurant?

Amy: L'Auberge du Louvre along Rue sauval

Amy: $\quad$ and when $i$ asked for the bill, he asked me if $\mathrm{i}$ wanted coffee!

Dave: The coffee part is normal, and there are french terms for food, asking for 'a point' rather than medium etc.

Amy: yeah, a lot to learn about the french ways of doing things... i had already been in the restaurant for about 2 hours. they do take eating seriously (and slowly). the wine was good though. not sure about the dessert, some sorbet stuff, i just inhaled it as i was running late.

Ted: $\quad$ It amazes me to watch French children eat raw mince for breakfast.

Mary: $\quad$ I like my steaks rare. It is more about the quality of the meat IMHO...

Frank: Try any of the restaurants along rue de la Huchette, south side of river in front of Notre Dame, in Saint Michel. The best and original Normandie crêpes are there!

Amy: @H, agree, if the quality is good enough, you can even eat it raw :P @I oh yeah need to check out Saint Michel. i remember some of the best meals from my last trip was from that area!

The members' interpretation work on food is simultaneously an interpretation of Frenchness. The process is a mystification of Frenchness at the level of perception, continually adding new ways of 
interpreting it without consensus being reached. The first myth is represented in Amy's direct reference to the stereotype and her general assessment of steaks in France. The second one concerns the discussion whether it is impolite to take a photo in a French restaurant - this is left veiled in mystery, with no consensus. One myth after another, the construct of Frenchness becomes surrounded by an aura consisting of these myths, and it is kept open for more assumptions and knowledge to be added. In Extract 5, 'France' and 'French' are referred to six times in all. Every now and then, the speakers refer to Frenchness in their interpretation of how food is served or delivered. Similarly, in a trip in Italy, one member posts 'Dudes you are in Italy, queuing is part of the experience' to respond to the preceding the tourist experience sharing. It is widely common that the members resort to otherness in the interpretation work on authenticity.

Authenticity deriving from engagement with unmarked objects is morally obligatory for the tourist similar to how marked sights and attractions are compelling for them to visit. This can be demonstrated with how the actors express the preferences for food. One example case in point is 'back in hotel to rest my feet and think of what to eat for dinner. feel like sushi... i know i know i'm in france and should eat more french food but i haven't had really good sushi in a while.' In this example, the actor is considering having sushi and adds a justification because it is believed that one 'should' eat French food when in France. The option of having sushi instead of French food is deemed to call for the justification that 'i haven't had really good sushi in a while'. The usage of ' $\mathrm{i}$ know i know' conveys that the belief of sampling local food in tourism is commonly shared. Saying ' $\mathrm{i}$ know i know' is an attempt to forestall potential incoming comments stating diverging opinions. Since he/she is already aware of the issue, the others do not have to suggest him/her to try the local food.

In contrast, in a trip to Japan, the choice of sushi is taken for granted and preferred with no such justification, as shown in the example - 'What's a trip to Japan without some quality sushi with quality views from 50F [the name of a Japanese restaurant]?' which is accompanied with a 
picture of sushi. Likewise, when travelling in Germany, 'Can't go wrong with local sausage and beer' is the expression. While marketing and management research treats tourism as consumer experience, social science tourism research views it through the peak experiences that tourists derive from sights and attractions, as well as activities such as eating, sleeping and playing as shown in both this study and the existing literature (Mak et al., 2012; Everett and Aitchison, 2008; Quan and Wang, 2004). Though sights are frequently mentioned in the members' communication, they are usually not dwelt on extensively. In comparison, the members usually share their experiences as consumers at greater length. In other words, usually their longer conversations are not on the Leaning Tower in Pisa or Fuji Mountain in Japan but about seemingly trivial topics close to daily experience, such as food and shopping. The members do not necessarily relate the tourist experience to everyday life by contrasting the ordinary and the extraordinary. Ordinary activities such as having coffee and donuts or buying clothes also are represented as an important part of the tourist experience.

\section{Construction of Existential Authenticity}

As introduced earlier, existential authenticity is situated in one's being and doing rather than in gazing upon toured objects and sights as a spectator. It is commonly represented in terms of getting off the routine track - that is, in relation to the norm of normlessness or freedom from daily constraints. In various ways, members express the touristic pleasure gained from a break from the ordinary and the possibility to have more autonomy to be one's authentic self. Every now and then, the motive of being spontaneous and free is presented in the middle of a conversation, as in 'Having a cocktail (maybe two) to cool down and figure out what to do this afternoon,' 'never gonna know when it'll happen, just like this trip!', and 'Let's see what adventures await us tomorrow!'

Tourism as one type of leisure is indeed closely associated with freedom (Bregha, 1980). It is what people do in their 'free' time in response to their personal interests while 'free' from many 
constraints, such as the necessity of labour and production. This quest for freedom that is so pronounced in the representation of the tourist experience is often articulated by weighing it against rules defining appropriate behaviour. Indeed, one theme in the online conversations is to indicate that a social norm has been broken. While it underlines the liminal experience of tourism, it also enables members to acknowledge the existence of social norms and to give justifications to breaking them while being a tourist. Extract 2 is a good example.

\section{Extract 2. 'Took a tram [in Amsterdam] without paying for it'}

Rose: Took a tram without paying for it (well, i didn't know how)

Alan: As you don't speak the local language you'd be forgiven anyway :)

Rose: I wouldn't have mind walking (was around HRC area) but didn't want to be late for my tour

In the conversation Rose first explains that she did not pay for the tram ticket because she does not know how to do it. Then, Alan adds one more reason, with 'since you don't speak the local language you would be forgiven anyway'. Finally, Rose's reply offers the justification that she took the tram instead of walking because she did not want to miss the tour. Thus, as a violation of a social convention, the act of not buying a tram ticket is justified three times therein. In this way, the expression of freedom is underlined while simultaneously honouring the rule that one should buy a ticket when taking a tram.

Another way in which the expression of freedom is coupled with social conformity is to consult others about proper behaviour. For instance, as in the post of 'Would you think me weird if $i$ found cable shopping fun?' uncertainty is communicated about the worthiness of shopping for computer cables as a leisure activity in tourism even though it is fun for the individual. Such asking for and giving social confirmation occurs rather often in the conversations. 
In the communication of existential authenticity, attending to social conventions is a way to contextualise the tourist experience and demonstrate one's awareness of the online community. Negotiating proper behaviour and identifying with others are ways by which members build and maintain social relationships in terms of the rationale of positive politeness to make the members feel good about their self (Brown and Levinson, 1987). They serve to manage the self-image and avoid being too different and deviant from the group. The members assure each other that one is doing the right thing, making good purchases, and so on. On the other hand, by evoking the point that they do things that could be deemed odd, members show that they are not too bound by social conventions: they are given permission to being unconventional in an acceptable manner.

Besides negotiating social conformity, one more instance of identifying with the online community in the communication of existential authenticity is the sharing of portraits. Portraits, especially group portraits, reproduce reality with documentation of high points in tourism and construct a 'we-ness'. Out of all the 235 photos published in the studied groups, there are 65 portraits of either individuals or groups. Typically the portraits are taken with certain sights included, e.g., wearing a Venetian Mask from the trip in Venice or standing beside David Beckham's wax image at Madame Tussauds Museum in London, or with elements signifying authenticity, e.g., dressed in Kimono in Tokyo or holding a big glass of beer in Berlin.

In the composition of the photos, smiling faces instead of the sights occupy the centre of the images depicting moments of happiness. The photographed individuals usually gaze at the camera i.e., eye contact is made with the viewers of the photos. The majority of the photos are mediumclose and close shots with camera being placed from a frontal angle, i.e., the upper body or the head and shoulders. These particular manners in the design with composition, camera distance and angle foreground a social or personal distance and intimate social relationships (Kress and Van Leeuwen, 2006), leaving the tour sights to the background, which is sometimes even unrecognisable. 


\section{Experientialisation in the Entwinement of Object-related and Existential Authenticity}

To summarise and theorise the findings, we propose to use the term experientialisation to characterise how the tourist experience is contextualised in SNSs. Related to the discussion on the experience society (Schulze, 1992) and mentioned in 'experience marketing' (Pine and Gilmore, 1998), experientialisation means here the particular ways that individuals collectively interpret the authentic tourist experience with foregrounding individuals' personal experience. The mechanism of experientialisation can be explained by highlighting the following aspects.

First, experientialisation depicts a particular way conversations develop. As we have mentioned, though conversations often start with marked tour objects, they usually do not dwell on the objects extensively. In comparison, the members usually share their experiences as consumers at greater length. In other words, usually their longer conversations do not deal with the tour sights but seemingly trivial topics close to daily experience, such as food and shopping. There are plenty of instances of the members talking about food and purchases such as boots, keyboards, and cables, but only rarely do they engage in extensive discussion of tourist attractions.

Second, experientialisation is realised by showing personal involvement. By this we mean that people are engaged in defining themselves: what they like and dislike, how they live their lives, and how they relate their preferences to those of their friends. This is evident in the frequent use of first and second person pronouns such as 'I', 'me', 'you', 'my', and 'your'.

One instantiation is how the themes are organised in the language use. Consider the sentences 'Amsterdam is interesting!' and 'We are enjoying everything in Prague'. In the former case, 'Amsterdam' is used as the theme and in the latter 'We' is the theme. Scrutinising the data from this perspective shows that person pronouns are usually the themes, whereas place referents are far more commonly used to denote a circumstance rather than as a theme. This suggests that, although visiting touristic sights are presented as an obligatory thing by certain linguistic markers, what is 
foregrounded is interest in each other rather than tour objects and sights. That is why there is so much talk that indicates existential authenticity. Accordingly, place is only a circumstance for this talk. On the other hand, references to otherness also serve identity construction. Another culture and the natives' habits provide a mirror to oneself. By for instance discussing local food and manners members relate themselves to a different culture: how they differ from it, and how they think it is acceptable to behave in the strange setting.

Furthermore, experientialisation of authenticity in SNSs is embedded in positive politeness culture. Interaction in the SNSs serves the function of bonding and maintaining social relations within the group. Consequently, in the conversations, positive politeness is widely employed to claim common ground and show interest in the others. After prolonged interaction, the topics of conversation are scoped to selected happenings and beings that could develop into casual, insignificant, and non-serious conversations in line with common interests. With topics that are close to daily experience, it is easier to prompt other individuals to share experience and knowledge in casual, less significant, and non-serious ways than by referring to sights and attractions such as the Mona Lisa and Louvre, which resonates with other studies on SNSs reporting on the 'talking small' culture (Frosh, 2012; Marwick and boyd, 2011; Schandorf, 2012; Vetere et al., 2005). One example of this virtual culture that prefers phatic communication (Schandorf, 2012; Malinowski, 1923/1989; Lomborg, 2012) is the frequent use of formulaic greetings. Postings such as 'Have fun!' 'Enjoy it!' and 'Have a safe trip!' are used over 180 times. For the members the formulaic greetings serve the function of acknowledging the recognition of each other's presence and companionship. These expressions offer an explorative ground for the members to find out whether or not the other parties are interested in further interaction.

Finally, experientialisation contests the fine line between object-related and existential authenticity. The two are inseparable in the communication of the tourist experience and embedded in each other with different strategies. For example, tourist portraits capturing happy moments 
during traveling often include tourist sights at the background. Similarly, the talk of sights and attractions typical of object-related authenticity often migrates to insignificant topics for the members to show interest in and give attention to each other and thereby refresh the social relationships.

In this entwinement, the pursuit of object-related authenticity is favoured more strongly than existential authenticity. As mentioned earlier, when members refer to sights and attractions, they are pointed to as more obligatory than optional; e.g., 'can't go wrong with local sausage and beer', and 'but i have to check out the louvre' (emphasis added). In contrast, when existential authenticity is presented in the data, it is favoured but not as strongly as object-related authenticity. Examples include 'Maybe wonder aimlessly' and 'Would you think me weird if i found cable shopping fun?' (emphasis added). In another case, when an individual was feeling unwell during the trip and decided to take part in more relaxing activities, she put it thus: 'Also booked a massage for tomorrow, and a philharmonic concert for tonight. Still not quite recovered yet so taking it easy' (my emphasis). Massages and concerts here are taken to be suitable activities for when one is supposed to 'take it easy' as a compromise and a secondary option after object-related authenticity.

\section{Conclusion and Discussion}

The aim of this study was to explore how the tourist experience is communicated in the context of SNSs with authenticity as the focus of the analysis. Based on the examination of the construction of object-related authenticity and existential authenticity, we proposed that the contextualisation of the tourist experience communication in SNSs can be characterised as experientialisation.

Experientialisation depicts several specific language use patterns embedded in positive politeness culture and the entwinement of object-related and existential authenticity.

The proposed concept of experientialisation contributes to the area of tourist experience research both theoretically and in practice. In the existing literature, discussion on 
experientialisation usually starts from the perspective of tourist destination management or marketing, underlining a change of focus from the product and service to experience. That bias is challenged by the emerging views in the scholarship emphasising the active roles played by the tourists. This study offers an alternative to understanding how the tourist experience is produced discursively by travellers. The results are relevant also for tourism marketing. Upon recognition of the marketing value of the Internet as a communication channel, different communication strategies have been seen. This study demonstrates that attending to the ways travellers themselves construct the tourist experience in their online interaction can give marketing professionals valuable insights regarding their communication strategies and tactics.

In addition to revealing the contextualisation of the tourist experience sharing in SNSs, this study also contributes to the understanding of authenticity. First, object-related and existential authenticity appeal to tourists with different mechanisms. Object-related authenticity appeals to tourists with morality: engaging with otherness and alien cultures is morally valued and favoured. But existential authenticity gets individuals to engage in conversation more often. Second, in the construction of object-related authenticity, unmarked objects are usually more attractive to conversation making than marked ones, i.e., individuals are more willing to tell and remark on the activities such as eating and shopping, which are close to everyday life. Third, though authenticity has served as a powerful analytical concept, it should be noted that in the discursive field, the different types of authenticity are usually inseparable in a topical conversation.

Due to scarcity of research, we do not really know how tourists - a consumer group mostly comprising individuals living in affluent societies - used to share their travel experiences before the Internet and the arrival of SNSs. If we assume that online chatting with friends is not entirely unlike people sharing their travel experiences around a kitchen table, we could argue that SNSs just give us easy access to how it is done in practice. It is certainly true that now the tourist experience is shared already during the trip, whereas previously it could only happen afterwards. But, for 
instance, the tourists' snapshots haven't completely changed because of it: in the old times, also, individuals, friends and families took portraits in front of tourist sights. Instead of assuming a historical change, we suggest that the touristic quest for object-related authenticity has always been entangled with an existential orientation, because it is linked with identity construction. As tourists people are captivated by otherness because it provides new perspectives on their own lives. They can reflect on and express their likings by relating them to different tastes and manners. And different forms of tourism are not only about defining who 'I' am or who 'we' are in relation to others; it is also about finding new sides or developing them in oneself through taking challenges such as mountain climbing. Or consider second home tourism (Coppock, 1977; Gallent et al., 2005), the attraction of which comes primarily from the experience of being in a different place and breaking off from the routines of ordinary everyday life (Alasuutari and Alasuutari, 2010). In their second homes people are engaged in activities like building or gardening that are very different from their city roles, and they can also imagine being someone else; for instance a British interviewee who owned a house in France enjoyed playing the role of a genuine French peasant (Chaplin, 1999: 46). In this sense in different forms of tourism the otherness of the place and the activities in it help us reflect on and meet ourselves: who we are and what is important in life. Nowadays these reflections and experiences are also shared online, whether we are on holiday or not. In this way being away as a tourist and being present is further blurred.

When considering the limitations of this study, the sample size and data selection are the main factors that affect the generalisability. The texts are collected from only one individual's social networks, which is why it could be assumed that the demographic profiles of the participants shape the language use and interaction patterns. On the other hand, the fact that the findings are in line with several previous studies on related phenomena suggests that the discourses employed by the members stem from a global culture of modernity. Further research examining diverse groups in SNSs from different cultures is however needed. 


\section{Notes}

${ }^{1}$ Google+ actually was launched in June 2011. Before that it was Google Buzz that largely shared the essential affordances of Google+. Later Buzz was replaced by Google+ with upgraded features and accordingly the community migrated to Google+.

${ }^{2}$ The participants only include those who has posted and contributed in the text production. The two communities are somewhat redundant. Some connections in Google+ are also there in Facebook.

${ }^{3}$ The names in the extracts in this article are pseudo for privacy protection.

\section{References cited}

Alasuutari P and Alasuutari M. (2010) Mökkihulluus: Vapaa-ajan asumisen taika ja taito [The Cottage Craze: The Magic and Gist of Free Time Dwelling], Rovaniemi: Lapin yliopistokustannus.

Berger P and Luckmann T. (1966) The social construction of knowledge: A treatise in the sociology of knowledge, New York: Doubleday.

Bizirgianni I and Dionysopoulou P. (2013) The influence of tourist trends of youth tourism through social media (SM) \& information and communication technologies (ICTs). Procedia-Social and Behavioral Sciences 73: 652-660.

Bregha FJ. (1980) Leisure and freedom re-examined. In: Goodale TL and Witt PA (eds) Recreation and leisure: Issues in an era of change. Madison: Venture Publishing, 47-54.

Brown P and Levinson SC. (1987) Politeness: Some Universals in Language Usage, Cambridge: Cambridge University Press.

Buhalis D and Foerste M-K. (2013) SoCoMo marketing for travel and tourism. Information and Communication Technologies in Tourism 2014. Springer, 175-185.

Buhalis D and Law R. (2008) Progress in information technology and tourism management: 20 years on and 10 years after the Internet-The state of eTourism research. Tourism management 29: 609-623.

Chaplin D. (1999) Consuming Work/Productive Leisure: The Consumption Patterns of Second Home Environments. Leisure Studies 18: 41-55.

Cohen E. (1988) Authenticity and commoditization in tourism. Annals of Tourism Research 15: 371-386.

Cohen E and Cohen SA. (2012) Authentication: Hot and cool. Annals of Tourism Research 39: 1295-1314.

Coppock JT. (1977) Second homes: Curse or blessing?, Oxford: Pergamon. 
Cox C, Burgess S, Sellitto C, et al. (2009) The role of user-generated content in tourists' travel planning behavior. Journal of Hospitality Marketing \& Management 18: 743-764.

Dinhopl A and Gretzel U. (2015) Changing practices/new technologies: Photos and videos on vacation. Information and Communication Technologies in Tourism 2015. Springer, 777788.

Dinhopl A and Gretzel U. (2016a) Conceptualizing tourist videography. Information Technology \& Tourism 15: 395-410.

Dinhopl A and Gretzel U. (2016b) Selfie-taking as touristic looking. Annals of Tourism Research 57: $126-139$.

Ess C and AoIR. (2002) Ethical decision-making and Internet research: Recommendations from the aoir ethics working committee. http://aoir.org/reports/ethics.pdf.

Everett S and Aitchison C. (2008) The role of food tourism in sustaining regional identity: A case study of Cornwall, South West England. Journal of Sustainable Tourism 16: 150-167.

Frosh P. (2012) The showing of sharedness: Monstration, media and social life. Divinatio: 123-138.

Gallent N, Mace A and Tewdwr-Jones M. (2005) Second homes: European perspectives and UK policies, Aldershot: Ashgate.

Gilbert GN and Mulkay M. (1984) Opening Pandora's box: A sociological analysis of scientists' discourse, Cambridge: Cambridge University Press.

Guerra A, Gosling M and Carvalho T. (2015) Social networks and generations X and Y: Dissemination and tourism experience sharing. Rosa dos Ventos 7: 302-315.

Heritage J. (1984) Garfinkel and Ethnomethodology, Cambridge: Polity Press.

Huang Y, Basu C and Hsu MK. (2010) Exploring motivations of travel knowledge sharing on social network sites: an empirical investigation of US college students. Journal of Hospitality Marketing \& Management 19: 717-734.

IPK International. (2015) ITB world travel trends report 2015/2016. Available at: http://www.itbberlin.de/media/itbk/itbk_dl_all/itbk_dl_all_itbkongress/itbk_dl_all_itbkongress_itbkongres s365/itbk dl all itbkongress itbkongress365 itblibrary/itbk dl all itbkongress itbkongres s365_itblibrary_studien/ITB_World_Travel_Trends_Report_2015_2016.pdf.

Jansson A. (2002) Spatial phantasmagoria. The mediatization of tourism experience. European Journal Of Communication 17: 429-443.

Jansson A. (2007) A sense of tourism: New media and the dialectic of encapsulation/decapsulation. Tourist Studies 7: 5-24.

Kane MJ. (2012) Professional adventure tourists: Producing and selling stories of 'authentic' identity. Tourist Studies 12: 268-286.

Kim JJ and Fesenmaier DR. (2015) Sharing tourism experiences: The posttrip experience. Journal of Travel Research: 1-13.

Kress GR and Van Leeuwen T. (2006) Reading images: the grammar of visual design, London: Routledge.

Larsen J, Urry J and Axhausen KW. (2007) Networks and tourism: Mobile social life. Annals of Tourism Research 34: 244-262.

Lau RW. (2010) Revisiting authenticity: A social realist approach. Annals of Tourism Research 37: $478-498$.

Lean GL. (2012) Transformative travel: A mobilities perspective. Tourist Studies 12: 151-172.

Lomborg S. (2012) Negotiating privacy through phatic communication: A case study of the blogging self. Philosophy \& Technology 25: 415-434. 
Lugosi P. (2014) Mobilising identity and culture in experience co-creation and venue operation. Tourism management 40: 165-179.

Lugosi P. (2016) Socio-technological authentication. Annals of Tourism Research 58: 100-113. MacCannell D. (1976/1989) The tourist: A new theory of the leisure class, New York: Schocken Books.

Mak AH, Lumbers M and Eves A. (2012) Globalisation and food consumption in tourism. Annals of Tourism Research 39: 171-196.

Malinowski B. (1923/1989) The problem of meaning in primitive languages. In: Ogden CK and Richards IA (eds) The meaning of meaning: A study of influence of language upon thought and of the science of symbolism. New York: Harcourt, Brace and World, 296-336.

Markham A, Buchanan E and AOIR. (2012) Ethical decision-making and Internet research 2.0: Recommendations from the aoir ethics working committee. http://aoir.org/reports/ethics2.pdf.

Marwick AE and boyd d. (2011) I tweet honestly, I tweet passionately: Twitter users, context collapse, and the imagined audience. New Media \& Society 13: 114-133.

Mkono M. (2011) The Othering of Food in Touristic Eatertainment: A Netnography. Tourist Studies 11: 253-270.

Munar AM and Jacobsen JKS. (2014) Motivations for sharing tourism experiences through social media. Tourism management 43: 46-54.

Neuhofer B, Buhalis D and Ladkin A. (2014) A typology of technology - enhanced tourism experiences. International Journal of Tourism Research 16: 340-350.

Oliveira E and Panyik E. (2015) Content, context and co-creation: Digital challenges in destination branding with references to Portugal as a tourist destination. Journal of Vacation Marketing 21: 53-74.

Parra-López E, Bulchand-Gidumal J, Gutiérrez-Taño D, et al. (2011) Intentions to use social media in organizing and taking vacation trips. Computers in Human Behavior 27: 640-654.

Pearce J and Moscardo G. (2015) Social representations of tourist selfies: New challenges for sustainable tourism. BEST EN Think Tank XV, 17-21 June 2015. Skukuza, Mpumalanga, South Africa, 59-73.

Pearce P, Oktadiana H and Wang Z. (2016) "How do I look?": An ethological study of posing for the tourist photograph [online]. In: Scerri M and Hui LK (eds) CAUTHE 2016: The Changing Landscape of Tourism and Hospitality: The Impact of Emerging Markets and Emerging Destinations. Sydney: Blue Mountains, 185-201.

Pine I, B. Joseph; and Gilmore JH. (1998) Welcome to the experience economy. Harvard Business Review 76: 97-105.

Potter J. (1996) Representing reality: Discourse, rhetoric and social construction, London: Sage.

Potter J and Wetherell M. (1987) Discourse and social psychology: Beyond attitudes and behaviour, London, Newbury Park, Calif: Sage.

Potter J and Wetherell M. (1994) Analyzing discourse. In: Bryman A and Burgess R (eds) Analyzing qualitative data. London and New York: Routledge, 47-66.

Quan S and Wang N. (2004) Towards a structural model of the tourist experience: An illustration from food experiences in tourism. Tourism management 25: 297-305.

Rihova I, Buhalis D, Moital M, et al. (2015) Conceptualising customer-to-customer value cocreation in tourism. International Journal of Tourism Research 17: 356-363.

Schandorf M. (2012) Mediated gesture: Paralinguistic communication and phatic text. Convergence: The International Journal of Research into New Media Technologies. 
Schulze G. (1992) Die Erlebnisgesellschaft: Kultursoziologie der Gegenwart, Frankfurt: Campus.

Steiner CJ and Reisinger Y. (2006) Understanding existential authenticity. Annals of Tourism Research 33: 299-318.

Tussyadiah IP and Fesenmaier DR. (2009) Mediating tourist experiences: Access to places via shared videos. Annals of Tourism Research 36: 24-40.

Uriely N. (2005) The tourist experience: Conceptual developments. Annals of Tourism Research 32: 199-216.

Urry J. (2003) Social networks, travel and talk. The British Journal of Sociology 54: 155-175.

van Nuenen T. (2015) Here I am: Authenticity and self-branding on travel blogs. Tourist Studies: 121.

Vetere F, Gibbs MR, Kjeldskov J, et al. (2005) Mediating intimacy: Designing technologies to support strong-tie relationships. SIGCHI Conference on Human Factors in Computing Systems. Portland, Oregon, USA: ACM, 471-480.

Wang N. (1999) Rethinking authenticity in tourism experience. Annals of Tourism Research 26: 349-370.

White NR and White PB. (2007) Home and away: Tourists in a connected world. Annals of Tourism Research 34: 88-104.

Wozniak T, Liebrich A, Senn Y, et al. (2016) Alpine Tourists' Willingness to Engage in Virtual CoCreation of Experiences. Information and Communication Technologies in Tourism 2016. Springer, 281-294.

Xiang Z and Gretzel U. (2010) Role of social media in online travel information search. Tourism management 31: 179-188.

Zeng B and Gerritsen R. (2014) What do we know about social media in tourism? A review. Tourism Management Perspectives 10: 27-36.

Zigon J. (2008) Morality: An anthropological perspective, Oxford: Berg. 